\title{
SPECIES TRAITS AS PREDICTORS OF LEPIDOPTERAN COMPOSITION IN RESTORED AND REMNANT TALLGRASS PRAIRIES
}

\author{
Keith S. Summerville, ${ }^{1}$ Christopher J. Conoan, and Renae M. Steichen \\ Department of Environmental Science and Policy, Drake University, Des Moines, Iowa 50311-4505 USA
}

\begin{abstract}
Restoration ecologists are increasingly turning to the development of trait-filter models, which predict how evolved traits limit species membership within assemblages depending on existing abiotic or biotic constraints, as a tool to explain how species move from a regional species pool into a restored community. Two often untested assumptions of these models, however, are that species traits can reliably predict species' broadscale distribution and that the effects of traits on community membership do not vary between restored and remnant habitats. The goals of this study were to determine whether combinations of ecological traits predispose moth species toward recolonization of restored prairies and to assess the degree to which restored prairies contain moth assemblages comparable with prairie remnants. In 2004, we collected 259 moth species from 13 tallgrass prairie remnants and restorations in central Iowa. Principal components analysis (PCA) was used to identify significant combinations of ecological traits that were shared by groups of moth species. Logistic regression was then employed to test for significant effects of the trait combinations on the frequency of prairie sites occupied by moth species. PCA partitioned moth traits into four axes that explained a total of $81.6 \%$ of the variance. Logistic regression detected significant effects for all four PCA axes on the fraction of sites occupied by moths. Species frequently filtered from the regional species pool into prairies were those that had long flight periods and were multivoltine, displayed a feeding preference for legumes but not other forb families, and were regionally abundant but relatively small in body size. Ordination revealed significant differences in moth communities among prairies, suggesting that species traits and habitat characteristics likely interact to create observed patterns of species recolonization of restorations. Thus, the optimal approach to restoring the lepidopteran fauna of tallgrass prairies may involve locating prairie plantings adjacent to habitat remnants.
\end{abstract}

Key words: assembly rules; biodiversity; moths; principal components analysis; restoration ecology; tallgrass prairie; trait-filter models.

\section{INTRODUCTION}

The restoration of native animal communities is perhaps one of the greatest tests for how well theories of community ecology explain the processes that determine species membership within communities (Jordan et al. 1987). Unfortunately, restoration of faunal assemblages tends to be a rare event (e.g., Lockwood and Pimm 1999). Thus, restoration ecologists need to identify and explain local and regional constraints on faunal colonization so that practitioners can reduce impediments (see review by Temperton et al. [2004]). Because restorations are frequently used to replace one habitat type with another, it seems likely that species traits will significantly influence both the type of species filtered from the landscape into newly created patches and the length of time required for faunal convergence between restored and remnant patches.

Manuscript received 14 January 2005; revised 9 September 2005; accepted 21 September 2005. Corresponding Editor: J. B. Zedler.

${ }^{1}$ E-mail: keith.summerville@drake.edu
Zobel (1997) defined the term regional species pool to include species in a region that are capable of coexisting within a focal community. Species attain membership in a regional species pool through large-scale processes such as speciation and migration (Holt 1993). Local communities, however, are rarely composed of the entire regional set of species, and numerous authors have advocated models based on assembly rules to predict how species are sorted from the regional pool into local communities (e.g., Townsend et al. 1997, Zobel et al. 2000, Chase 2003). In general, species should be capable of joining a local community when they are capable of dispersing to a site and have their resource requirements met (Liebold et al. 2004). More complex assembly rules seek to predict how species traits interact with biotic and abiotic variables within a site to determine whether individuals are capable of dispersing to and establishing a population within a particular site (e.g., trait-filter models; see Stoner and Joern 2004). Importantly, significant effects revealed by fitting trait-filter models are indicative of potential obstacles to restoring specific species assemblages and may prove useful for influencing how management is applied to a system in order to 
direct community reassembly (e.g., see papers in Temperton et al. [2004]).

Insects, however, pose at least two major challenges to developing trait-filter models to explain local species composition. First, the regional species pool is difficult to quantify for most taxa (e.g., Longino et al. 2002). Many studies of local and regional species pools for insects have concentrated on a single resource base (e.g., one host plant) rather than series of habitats (Cornell and Washburn 1979, Lawton 1990, Cornell and Lawton 1992, Novotny et al. 2003). Second, even when ecologists exert substantial effort in collecting specimens, data on species' life history may be lacking (New 1999). Therefore, progress in developing predictive assembly rules for restored ecosystems has been rather slow (but see Stoner and Joern 2004).

The Lepidoptera (butterflies and moths) are one order of insects for which quantifying the regional species pool and locating data on species natural history may be straightforward tasks (Robinson et al. 2002, Summerville et al. 2003, Lewis et al., in press). Because moths are more species diverse than butterflies in tallgrass prairies, moths may be suitable taxa for answering general questions about the exchange of species between regional and actual species pools within restored prairies. In this case, restoration ecologists may desire to determine whether the frequency of site occupancy is correlated with traits such as diet specialization, voltinism, regional abundance, or body size. Specific hypotheses may be derived from existing macroecological theory, which suggests that smaller, more generalist species tend to be the most widely distributed (and thus the species expected to be most frequently encountered in restored ecosystems; Brown 1995, Blackburn and Gaston 2003).

Numerous studies have attempted to demonstrate how assembly rules might be used to predict changes in species composition within habitats over time, but the results have been equivocal (e.g., see reviews by Weiher and Keddy [1999] and Temperton et al. [2004]). For example, body size is an important predictor of species distribution and abundance within local communities for British but not European Lepidoptera (Gaston and Reavey 1989, Brändle et al. 2002). Diet breadth and diet specialization are significant determinants of species membership for moths within forest communities rather than body size or regional abundance (Summerville and Crist 2003, Summerville 2004). Some studies have also identified a positive correlation between the degree of polyphagy observed in the Lepidoptera and both the level of multivoltinism within species and, perhaps, the number of sites within a region occupied by species (Spitzer et al. 1984). Several recent studies have illustrated the importance of assembly history in ecological communities (Chase 2003, Shurin and Srivastava 2004), with some studies suggesting that the initial fauna to colonize a site may cause local communities to diverge in species composition when the regional species pool is sufficiently diverse (e.g., Fukami 2004). Ulti- mately, species traits may interact with local and regional habitat characteristics, such as plant community composition, to influence species recolonization of restored habitats (Waltz and Covington 2004, Summerville et al. 2005).

The goals of this study were to determine whether combinations of traits predispose moth species toward becoming members of the local community within restored prairies of Iowa and to assess the degree to which restored prairie habitats possess lepidopteran communities similar to those in remnant prairies. We used a two step analytical process to determine how species traits affected colonization of prairie sites by moths. First, we used principal components analysis (PCA) to identify combinations of traits that were highly correlated but also shared by specific suites of species from the regional species pool. Second, we used logistic regression to model the effect of species traits summarized as PCA scores on the frequency of restoration sites occupied by moth species. We hypothesized that largebodied, multivoltine and regionally abundant moths would be the most frequently encountered in restored ecosystems if membership within restored communities is largely constrained by dispersal events. In this case, large species may possess greater flight ability or be capable of recolonizing a prairie from a greater distance, while multivoltine and regionally abundant species would have a greater chance of having at least a few individuals colonize newly planted sites each year. Alternatively, we hypothesized that larval host plant breadth and type of host plant utilized would be the most significant determinant of species composition in restored prairies if community structure is primarily determined by resource matching between moth species and specific host plants. Finally, we used an ordination technique to test whether differences in species traits were correlated with systematic differences in lepidopteran community composition in restored and remnant prairie habitats.

\section{Methods \\ Study sites}

We sampled moths from 13 tallgrass prairie sites in central Iowa (USA) comprising: prairie remnants (five sites), prairie restorations (five sites each $\geq 5$ years old), and newly planted prairies (three sites seeded in spring 2004; Table 1). All 13 sites were located in the southcentral portion of the Central Tallgrass Prairie Ecoregion (CTP), and the maximum separation distance among sites was $\sim 35 \mathrm{~km}$ (mean separation distance $10.33 \mathrm{~km}$ ). Before European settlement, the CTP was among the most mesic and most widespread of all tallgrass associations on Earth (Ricketts et al. 1999). Dominant grass species in this ecoregion were Andropogon gerardii (big bluestem), Panicum virgatum (switch grass), and Sorghastrum nutans (Indian grass) (Rosburg 2001). Forbs in the families Asteraceae, Fabaceae, Lamiaceae, and Rosaceae also contributed significantly 
TABLE 1. Habitat and management characteristics for 13 prairie sites used for moth sampling in 2004, in south-central Iowa, USA.

\begin{tabular}{|c|c|c|c|c|c|c|}
\hline Site name & Habitat type & Location & Size (ha) & $\begin{array}{l}\text { Seed ratio used } \\
\text { in restoration } \\
\text { (grass/forb) } \dagger\end{array}$ & $\begin{array}{l}\text { Time since } \\
\text { last burn } \\
\text { (yr) }\end{array}$ & $\begin{array}{c}\text { Observed } \\
\text { moth species } \\
\text { richness }\end{array}$ \\
\hline Puccoon prairie & remnant & $41^{\circ} 44^{\prime} 07^{\prime \prime} \mathrm{N}, 93^{\circ} 21^{\prime} 51^{\prime \prime} \mathrm{W}$ & 4.5 & NA & 3 & 57 \\
\hline Sandhill prairie & remnant & $41^{\circ} 46^{\prime} 22^{\prime \prime} \mathrm{N}, 93^{\circ} 23^{\prime} 06^{\prime \prime} \mathrm{W}$ & 25.0 & $\begin{array}{c}\text { NA } \\
\text { (4/1 surrounding) }\end{array}$ & 2 & 90 \\
\hline Snyder farm & remnant & $41^{\circ} 46^{\prime} 20^{\prime \prime} \mathrm{N}, 93^{\circ} 29^{\prime} 15^{\prime \prime} \mathrm{W}$ & 16.8 & (6/1 surrounding) & 3 & 53 \\
\hline Neal Smith 1 & remnant & $41^{\circ} 33^{\prime} 51^{\prime \prime} \mathrm{N}, 93^{\circ} 15^{\prime} 43^{\prime \prime} \mathrm{W}$ & 4.2 & NA & never & 82 \\
\hline Errington wildlife area & remnant & $41^{\circ} 45^{\prime} 22^{\prime \prime} \mathrm{N}, 93^{\circ} 30^{\prime} 20^{\prime \prime} \mathrm{W}$ & 6.3 & $\begin{array}{c}\text { NA } \\
\text { (7/1 surrounding) }\end{array}$ & 5 & 46 \\
\hline Yellow Banks Park & restoration & $41^{\circ} 36^{\prime} 13^{\prime \prime} \mathrm{N}, 93^{\circ} 27^{\prime} 41^{\prime \prime} \mathrm{W}$ & 20.0 & $8 / 1$ & 1 & 58 \\
\hline Thomas Mitchell Park & restoration & $41^{\circ} 38^{\prime} 23^{\prime \prime} \mathrm{N}, 93^{\circ} 22^{\prime} 45^{\prime \prime} \mathrm{W}$ & 5.0 & $10 / 1$ & 1 & 41 \\
\hline Saylorville 1 & restoration & $41^{\circ} 44^{\prime} 58^{\prime \prime} \mathrm{N}, 93^{\circ} 40^{\prime} 53^{\prime \prime} \mathrm{W}$ & 4.5 & $2 / 1$ & never & 84 \\
\hline Saylorville 2 & restoration & $41^{\circ} 48^{\prime} 42^{\prime \prime} \mathrm{N}, 93^{\circ} 45^{\prime} 12^{\prime \prime} \mathrm{W}$ & 24.0 & $4 / 1$ & 1 & 66 \\
\hline Neal Smith 2 & restoration & $41^{\circ} 34^{\prime} 35^{\prime \prime} \mathrm{N}, 93^{\circ} 15^{\prime} 54^{\prime \prime} \mathrm{W}$ & 13.2 & $2 / 1$ & 2 & 103 \\
\hline Soccer complex & new planting & $41^{\circ} 33^{\prime} 58^{\prime \prime} \mathrm{N}, 93^{\circ} 34^{\prime} 20^{\prime \prime} \mathrm{W}$ & 1.4 & $2 / 1$ & never & 52 \\
\hline Softball complex & new planting & $41^{\circ} 39^{\prime} 04^{\prime \prime} \mathrm{N}, 93^{\circ} 31^{\prime} 50^{\prime \prime} \mathrm{W}$ & 8.0 & $3 / 1$ & never & 38 \\
\hline Glendale cemetery & new planting & $41^{\circ} 36^{\prime} 32^{\prime \prime} \mathrm{N}, 93^{\circ} 41^{\prime} 30^{\prime \prime} \mathrm{W}$ & 4.4 & $10 / 1$ & never & 18 \\
\hline
\end{tabular}

Notes: Prairie remnants were generally managed without direct seeding, although areas in the surrounding landscape were often also under restoration. Newly planted sites were seeded in May-June. NA, not available.

$\dagger$ Determined as the ratio (mass of grass seed)/(mass of forb seed) broadcast per hectare.

\$ Denotes that the original remnant has been enlarged through seeding and management of the surrounding landscape.

to plant diversity within the CTP (Ricketts et al. 1999, Rosburg 2001).

\section{Lepidoptera sampling}

Moths were collected using Universal blacklight traps (12-W, BioQuip Products, Rancho Dominguez, California, USA) powered by $12-\mathrm{V}, 26$ amp-h batteries. Blacklight traps are widely recognized as a standard method for sampling nocturnal Lepidoptera (Winter 2000). Traps were operated approximately every $10 \mathrm{~d}$ from 30 May to 30 August 2004, producing 78 total samples ( 13 sites $\times 6$ trap nights per site). On nights of operation, traps were placed on platforms $2 \mathrm{~m}$ above the ground and remained lit from 20:00 to 7:00 CDT (Central Daylight Time). Because weather and moonlight intensity affect sampling efficiency of blacklight traps, we trapped only on nights that had a minimum temperature $\geq 16^{\circ} \mathrm{C}$, no precipitation, and low levels of ambient moonlight (one-half to new moon phases) (Yela and Holyoak 1997). Collected specimens were frozen immediately following trap processing to facilitate curation and identification. Specimens requiring particular taxonomic expertise were forwarded to recognized experts. Voucher specimens have been deposited in the insect collections of Drake University, the University of Minnesota, and the United States Fish and Wildlife Service (Neal Smith National Wildlife Refuge).

\section{Measuring species traits}

We estimated body size as the mean of the maximum and minimum forewing length (in centimeters) as reported in Forbes (1923), Covell (1983), and other published monographs. Gaston and Reavey (1989) and Brändle et al. (2002) considered this approach valid for large data sets, especially for insects. We were able to obtain body size estimates for a total of 235 moth species. For each of these species, we were also able to obtain estimates for the duration of the adult flight period (Covell 1984, Lewis et al., in press), number of broods per season (i.e., voltinism; see Covell 1984, Miller 1987; also see monographs in the Moths of America North of Mexico series [Dominick et al. 19712005]), and number of host plant families used (Robinson et al. 2002). Further, we calculated forb dependence as the number of forb families reported as host plants divided by the total number of host plant families used by the larvae. Thus, species received a forb dependence score of 1 if they only relied on broad-leaved flowering plants as host resources. We also used an ordinal scoring system to measure the degree to which species were restricted in feeding preferences to the two most speciose families of prairie forbs: Asteraceae and Fabaceae (Robinson et al. 2002). Species were ranked on a scale of $0-2$ based on the degree to which they were specialized on each family ( 0 , complete lack of feeding on each family; 1 , species known to feed on either family but also known to feed on a number of other plant families; and 2, complete specialization on either family). Finally, we used the pooled number of individuals sampled for each species across all 13 field sites as a measure of regional abundance.

\section{Data analyses}

We used PC-ORD (Version 4, MJM Software Design, Gleneden Beach, California, USA) to generate a speciesaccumulation curve for 78 blacklight samples taken from the 13 field sites. This program generates an average species-accumulation curve by taking the mean of 1000 curves produced by randomly ordering the entry of samples into the analysis. We also estimated the number of species remaining to be sampled using the Chao2 estimator, which performs reasonably well when 
the number of rare species is large (Chao 1987). Sampling efficiency was then estimated as the number of species accumulated by sampling relative to the total number estimated to be present within the regional species pool.

We used logistic regression models to relate the fraction of the total number of sites occupied by each moth species to the eight traits measured for each species. The data for species traits, however, displayed a significant level of multicolinearity, which biases the results of regression models, particularly for significance tests of parameter estimates (Phillippi 1993). Therefore, we used principal components analysis (PCA) to identify combinations of species traits that were intercorrelated as recommended by Graham (2003). In this case, species possessing similar combinations of traits would share similar principal component scores and may be interpreted as facing the same limitations to community membership as other species with equivalent PCA scores. We performed the PCA using SAS (PROC PRINCOMP, SAS Institute 2000) and all eight of the measured species traits (see Table 3). Because the units of measurement for traits differed, we relied on the correlation matrix among variables to generate PCA scores rather than the covariance matrix (Graham 2003). One limitation that Phillippi (1993) recognized with regard to PCA is that the ecological interpretation of the principal components may be difficult. We attempted to overcome this problem by selecting 0.40 as the minimum loading coefficient required to include a trait variable in the interpretation of a given principal component (following Summerville et al. [2005]).

Logistic regression was then performed in SAS using the scores of the orthogonal principal components as predictor variables (SAS PROC LOGISTIC). We included only PCA axes that explained $>10 \%$ of the variance in species traits in our logistic regression. The fraction of total sites occupied by each species was modeled as the response variable. Model fit was assessed using the deviance statistic, which is distributed approximately as chi-square when the model degrees of freedom are large (Piegorsch and Bailer 1997). When using the deviance statistic, goodness-of-fit is interpreted somewhat differently compared to conventional significance tests because the null hypothesis is that the model appropriately describes the variation in the observed data. Thus, large $P$ values indicate insufficient evidence for rejecting the null hypothesis that the model fits. We also follow the recommendations of Nagelkerke (1991) and calculated the generalized $r^{2}$ parameter. Because we lacked a well resolved phylogeny to test for relationships among the species traits and moth taxa (families, subfamilies) included in this analysis, we followed the method of Koh et al. (2004) and created a second logistic regression model with a dummy variable used to code for lepidoptera families. The effect of moth family on frequency of occurrence was nonsignificant (Wald $\chi^{2}=$ $1.97, \mathrm{df}=1, P=0.167$ ) despite there being a correlation between moth family and the third principal component (Pearson $\chi^{2}=0.30, P<0.05$ ).

Finally, we used nonparametric multidimensional scaling (NMDS) to test for differences in moth species composition among the sites. A full description of NMDS is given in McCune and Grace (2002), but briefly NMDS seeks to reduce complex multispecies responses to environmental variation by reducing the stress (or variation) among sites while creating a smaller set of explanatory variables summarized in ordination axes. NMDS differs from other commonly employed ordination techniques in that NMDS differentiates among sampling units by ranking them according to their pairwise dissimilarity. We performed NMDS ordination with PC-ORD (Version 4, MJM Software Design, Gleneden Beach, California, USA). Moth community data consisted of log-transformed species abundance data for each prairie site. We used the Bray-Curtis statistic as the measure of ordination distance among moth communities because it is one of the most robust statistics for multivariate analysis, and it is little affected by large numbers of rare species. In addition, we followed the recommendation of McCune and Grace (2002) and used multiple runs of the NMDS algorithm with our real data (100 total runs) to avoid local stress minima, a problem that prevents the ordination from converging on the lowest possible stress value. We used 1000 Monte Carlo simulation runs to evaluate the significance of our final two ordination axes.

\section{RESUlTS}

In total, 259 species of moths and 3323 individuals were found in tallgrass prairie habitats in 2004 (Table 2). Of the 22 moth families collected, the Noctuidae, Tortricidae, and Crambidae were the most speciose. Nearly $45 \%$ of the individuals were Crambidae, a family that includes a moderately large number of species known to feed on graminoids as larvae (Table 2). The most widespread and abundant species were Caenurgina erechtea (Noctuidae), Haimbachyia squamularis (Crambidae), Crambus luteolellus (Crambidae), Crambus agitatellus (Crambidae), and Eucosma matutina (Tortricidae). Although we found a number of moth species from genera known to possess prairie dependent species (e.g., Eucosma [Tortricidae], Schinia, Papaipema [Noctuidae]), few of the moths encountered during our study are viewed as prairie dependent by taxonomic experts (e.g., Metzler et al. 2005). The species accumulation curve calculated from 78 samples of the regional species pool appeared to be gradually approaching saturation. The Chao2 estimator predicted that 134 additional species remained to be sampled from the region. Thus, our sampling accounted for $\sim 67 \%$ of the total species richness estimated to occur in our regional species pool. Finally, a preliminary analysis of covariance (PROC GLM, SAS Institute 2000) determined that species richness of moths did not significantly vary among prairie habitat types $(F=1.72$, df $=2,10, P>0.25$, 
TABLE 2. Species richness and abundance of Lepidoptera sampled from 13 prairie remnants and restorations in southcentral Iowa, USA.

\begin{tabular}{lcc}
\hline \hline \multicolumn{1}{c}{ Family } & Species richness & Abundance \\
\hline Elachistidae & 1 & 4 \\
Lyonetiidae & 1 & 1 \\
Ospostegidae & 1 & 1 \\
Plutellidae & 1 & 3 \\
Saturniidae & 1 & 1 \\
Yponmeutidae & 1 & 1 \\
Zygaenidae & 1 & 1 \\
Gracilariidae & 2 & 20 \\
Tineidae & 3 & 22 \\
Cosmopterigidae & 4 & 16 \\
Pterophoridae & 4 & 8 \\
Sphingidae & 4 & 4 \\
Acrolophidae & 5 & 31 \\
Notodontidae & 5 & 8 \\
Coleophoridae & 8 & 16 \\
Pyralidae & 8 & 174 \\
Gelechiidae & 15 & 34 \\
Arctiidae & 19 & 131 \\
Geometridae & 20 & 77 \\
Crambidae & 38 & 1494 \\
Tortricidae & 53 & 672 \\
Noctuidae & 64 & 604 \\
Total & 259 & 3323 \\
\hline
\end{tabular}

Note: Species were sampled from 15 May to 30 August 2004.

Table 1) or among sites of differing habitat area $(F=$ 0.21 , df $=1,10, P>0.25$, Table 1$)$. In general, however, moth species richness was moderately lower in smaller sites within a particular habitat type, and prairie remnants contained higher species richness than newly planted prairie restorations.

Principal components analysis partitioned the eight moth traits into four axes that each explained $>10 \%$ of the variance among species. Together, these four PCA axes explained $81.6 \%$ of the variance in traits among the 235 species for which we were able to obtain data. Three species traits made significant contributions to the first principal component: duration of the flight period, number of broods per year, and tendency to feed on legumes (Table 3). Species loading positively on this PCA axis (e.g., Plathypena scabra, Caenurgina erechtea, Mellila xanthometata) then possess prolonged flight periods and multiple broods per year with larvae displaying a strong preference for Fabaceae. Forb dependence and aster preference both loaded positively on the second principal component, so this axis described the degree to which the larvae of certain moth species only fed on the Asteraceae (Table 3). Many Tortricidae loaded positively on this PCA axis (e.g., species of Eucosma, Phaneta, Epiblema). Regional abundance of moth species loaded positively and body size loaded negatively on the third PCA axis. We interpreted this axis to indicate that species with the largest regional abundance were often smaller in body size. Indeed, the most regionally abundant moth species are of small body size relative to the breadth of body sizes considered in this study (Fig. 1). Finally, the fourth principal component was formed primarily by the negative factor loadings of host plant breadth and legume host plant use (Table 3). Species loading positively on this axis tended to be dietary specialists on plant families other than Fabaceae (or to a lesser extent Asteraceae), and included moths suspected of feeding on detritus (e.g., Zanclognatha spp.), aquatic plants (e.g, Munroessa spp.), or mints (Lamiaceae; e.g., Pyrausta spp).

The logistic regression model using the first four principal components as predictors of the fraction of sites occupied by each species was highly significant $($ deviance $=241.34, \mathrm{df}=230, P>0.29)$. The four PCA axes explained a total of $24 \%$ of the variation in species occurrences among the 13 prairie sites (Table 4). Furthermore, all four PCA axes were significant predictors of the fraction of sites occupied by moth species (Table 4 , df $=1, P<0.0001$ for all significance tests). The most widespread moth species possessed large positive scores on PCA axes one and three and negative scores on PCA axes two and four (Tables 3 and 4). Species most frequently filtered from the regional species pool into tallgrass prairie communities in Iowa are those that: (1) have long flight periods and are multivoltine (PCA axis 1), (2) display a feeding preference for legumes (PCA axis 1) but not the Asteraceae or other host plant families (PCA axes 2 and 4), and (3) are regionally abundant but relatively small in body size (PCA axis 3). Univoltine species with specialized dietary requirements (especially on Asteraceae) and larger body size were often restricted to a smaller subset of prairie sites (or a single site) within the entire region (e.g., late colonizers listed in Table 5).

Although habitat type and site area were not predictors of the species richness of moths in our study region, difference in species occurrence among sites did contribute to differences in community composition among the prairies (Fig. 2). The NMDS analysis

TABLE 3. Factor loadings from a principal components analysis of eight ecological traits measured from 235 moth species in south-central Iowa.

\begin{tabular}{lcrrr}
\hline \hline & \multicolumn{4}{c}{ Principal component axis } \\
\cline { 2 - 5 } \multicolumn{1}{c}{ Species trait } & \multicolumn{1}{c}{2} & \multicolumn{1}{c}{3} & \multicolumn{1}{c}{4} \\
\hline Body size $\dagger$ & 0.293 & -0.118 & $\mathbf{- 0 . 5 0 2}$ & 0.397 \\
Duration of flight period $\dagger$ & $\mathbf{0 . 5 0 8}$ & -0.279 & 0.084 & 0.306 \\
No. broods per year & $\mathbf{0 . 4 7 6}$ & -0.270 & 0.308 & 0.216 \\
No. host plant families & 0.386 & 0.227 & -0.348 & $-\mathbf{0 . 4 8 9}$ \\
Forb dependence§ & 0.097 & $\mathbf{0 . 5 9 7}$ & 0.299 & 0.360 \\
Regional abundance & 0.145 & -0.165 & $\mathbf{0 . 6 4 1}$ & -0.364 \\
Diet includes Asteraceae & 0.208 & $\mathbf{0 . 6 2 1}$ & 0.108 & 0.126 \\
Diet includes Fabaceae & $\mathbf{0 . 4 5 5}$ & 0.119 & -0.112 & $\mathbf{- 0 . 4 2 8}$ \\
& & & & \\
\end{tabular}

Notes: Factor loadings are only reported for those PCA axes that explained $>10 \%$ of the variation among moth species. Bold entries represent significant factor loadings for each PCA axis.

$\dagger$ Calculated as average wingspan of each species $(\mathrm{cm})$.

+ As reported in Lewis et al. (in press) and Covell (1983).

$\S$ Determined as the ratio of the number of forb host plant families/total number of host plant families used (data obtained from Robinson et al. [2002]). 


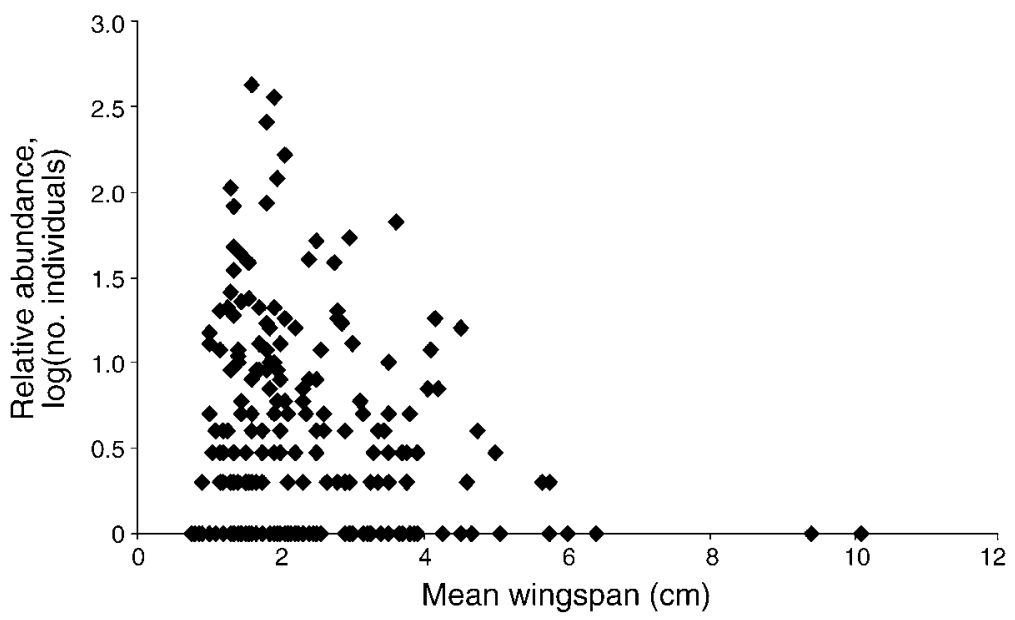

FIG. 1. Relationship between log-abundance of 235 moth species sampled from 13 tallgrass prairie sites and mean body size (measured as average wingspan). The modal body size was $2.0 \mathrm{~cm}$.

indicated that a two-dimensional ordination was optimal, and both axes were significant predictors of local species composition (Fig. 2). Together, these two ordination axes explained $88.8 \%$ of the variation in species composition among sites. Prairie sites clustered according to habitat type along the $x$-axis of the ordination diagram $\left(r^{2}\right.$ for axis $\left.1 \approx 0.67, P<0.005\right)$, with newly planted sites devoid of significant vegetation loading negatively on the $x$-axis and forb-rich prairie remnants loading more positively (Fig. 2). The newly planted sites contained moth species that were the most abundant regionally and that possess larvae known to feed on grasses (e.g., the moderately to small-bodied Crambus spp.), clovers, or sweet clovers (Fabaceae; Table 5). Restored prairie habitats and prairie remnants possessed a larger number of moths known to feed on Asteraceae, Rosaceae, and Lamianceae (Table 5), and differences in species composition among these sites were driven, in part, by a large number of unique species present within each location. Some spatial dependence may partly be indicated in site groupings along the $y$ -

TABLE 4. Results from a logistic regression model fitting the observed frequency of moth occurrence among 13 tallgrass prairie and restorations to the first four principal components extracted from variation in ecological traits for 235 moth species.

\begin{tabular}{lcccrc}
\hline \hline $\begin{array}{l}\text { Regression } \\
\text { parameter }\end{array}$ & df & $\begin{array}{c}\text { Parameter } \\
\text { estimate }\end{array}$ & SE & Wald $\chi^{2}$ & $P$ \\
\hline PCA axis 1 & 1 & 0.23 & 0.03 & 63.04 & 0.0001 \\
PCA axis 2 & 1 & -0.22 & 0.04 & 32.81 & 0.0001 \\
PCA axis 3 & 1 & 0.73 & 0.04 & 236.12 & 0.0001 \\
PCA axis 4 & 1 & -0.47 & 0.05 & 81.30 & 0.0001 \\
Intercept & 1 & -1.41 & 0.05 & 762.64 & 0.0001 \\
\hline
\end{tabular}

Notes: Factor loadings for the principal components are summarized in Table 3 . The overall logistic regression model was significant (deviance $=241.34, \mathrm{df}=230, P>0.29$ ), and the generalized $R^{2}$ value for the model was 0.24 . axis $\left(r^{2}\right.$ for axis $2 \approx 0.21, P=0.010$ ), especially for the Neal Smith and Saylorville sites, which both contain two replicates within large restored landscapes (Fig. 2). A post hoc Mantel test, however, suggested that spatial dependence was not significant (Mantel's $r=-0.10, P=$ 0.35) even though some site clusters in the NMDS ordination were in the same general geographic location (i.e., within $2.5 \mathrm{~km}$ of one another). Because of the limited number of sites used in this study, we suggest that the issue of spatial dependence remains unresolved. Interestingly, NMDS also revealed that there was considerably greater variation in moth communities for prairie remnants compared to older restorations (e.g., see axis 2 of Fig. 2).

\section{Discussion}

We found significant evidence that specific combinations of ecological traits increase the likelihood that moth species are found within local tallgrass prairie communities. Species most likely occurring in a prairie were those that possessed: long flight periods and multivoltine life cycles, a preference for larval feeding on legumes but little specialization on other forb families, and a large regional abundance with modal body size ( $\sim 2.1 \mathrm{~cm}$ wingspan; see Fig. 1). Interpreting the mechanisms that underlie how these combinations of species traits influence the probability of a species moving from a regional to actual species pool is often a more complex task (Zobel 1997). Assuming that species membership within local communities is partly a stochastic process (i.e., a "lottery"-type model), we suggest that significant effects of adult flight duration and number of broods per generation increase the probability that individuals from a given species will be passively sampled from the regional pool (Coleman et al. 1983, Garciá and Zamora 2003). The significant effect of regional abundance lends additional support for this explanation; regionally abundant species often possess 
TABLE 5. Hypothetical restoration categories for selected moth species based on their factor loadings in our PCA analysis.

\begin{tabular}{|c|c|c|}
\hline Widespread/initial colonizers & & Range-limited/late colonizers \\
\hline $\begin{array}{l}\text { Spilosoma virginica, F. (Arctiidae) } \\
\text { Achyra rantalis, Gn. (Crambidae) } \\
\text { Crambus agitatellus, Clem. (Crambidae) } \\
\text { Crambus luteolellus, Clem. (Crambidae) } \\
\text { Nomophila nearctica, Mun. (Crambidae) } \\
\text { Udea rubigalis, Gn. (Crambidae) } \\
\text { Orthonama centrostrigaria, Woll. } \\
\text { (Geometridae) } \\
\text { Caenurgina erechtea, Cram. (Noctuidae) } \\
\text { Macrochilo orciferalis, Wlk. (Noctuidae) } \\
\text { Phalaenostola laurentioides, Grt. } \\
\text { (Noctuidae) } \\
\text { Arta statalis, Grt. (Pyralidae) } \\
\text { Clepsis clemensiana, Fern. (Tortricidae) } \\
\text { Epiblema strenuana, Wlk. (Tortricidae) } \\
\text { Eucosma derelicta, Heinr. (Tortricidae) }\end{array}$ & $\begin{array}{l}\text { Holomelina immaculata, Reak. } \\
\text { (Arctiidae) } \\
\text { Haimbachia squamulella, Zell. } \\
\text { (Crambidae) } \\
\text { Platytes vobisne, Dyar. (Crambidae) } \\
\text { Pyrausta signatalis, Wlk. (Crambidae) } \\
\text { Xubidia panalope, Dyar. (Crambidae) } \\
\text { Faronta rubripennis, G. \& R. } \\
\text { (Noctuidae) } \\
\text { Leucania multilinea, Wlk. (Noctuidae) } \\
\text { Epiblema otiosana, Clem. (Tortricidae) } \\
\text { Eucosma matutina, Grt. (Tortricidae) } \\
\text { Olethreutes cespitana, Hbn. (Tortricidae) } \\
\text { Pelochrista scintillana, Clem. } \\
\text { (Tortricidae) } \\
\text { Phaneta clavana, Fern. (Tortricidae) } \\
\text { Phaneta ochrocephala, Wlsm. } \\
\quad \text { (Tortricidae) } \\
\text { Xenotemna pallorana, Rob. (Tortricidae) }\end{array}$ & $\begin{array}{l}\text { Aristotelia elegantella, } \mathrm{McD} . \\
\quad \text { (Gelechiidae) } \\
\text { Polygrammodes flavidalis, Gn. } \\
\quad \text { (Crambidae) } \\
\text { Pyrausta laticlavia, G. \& R. } \\
\quad \text { (Crambidae) } \\
\text { Pyrausta tyralis, Gn. (Crambidae) } \\
\text { Martyrhilda gracilis, Wlsm. } \\
\quad \text { (Elachistidae) } \\
\text { Cirrhophanus triangulifer, Grt. } \\
\quad \text { (Noctuidae) } \\
\text { Loxagrotis grotei, Franc. \& Todd } \\
\quad \text { (Noctuidae) } \\
\text { Papaipema cerussata, Grt. (Noctuidae) } \\
\text { Schinia oleagina, (Noctuidae) } \\
\text { Aethes patricia, (Tortricidae) } \\
\text { Eucosma giganteana, Riley (Tortricidae) } \\
\text { Eucosma ridingsana, Rob. (Tortricidae) } \\
\text { Epiblema tripartitana, Zell. (Tortricidae) } \\
\text { Phaneta radiatana, Wlsm. (Tortricidae) }\end{array}$ \\
\hline
\end{tabular}

Notes: Species were categorized as "initial colonizers" if they loaded positively on PCA axes 1 and 3, while "late colonizers" loaded positively on PCA axes 2 and 4. Species were considered "secondary colonizers" if they loaded positively on PCA axis 1 and either 2 or 4 . Widespread species occurred at $\geq 10$ sites, moderately distributed species occurred at 4-9 sites, and range-limited species were sampled from $\leq 3$ sites. Based on the results of this study, only restorations $>5 \mathrm{yr}$ old will contain species classified as secondary or late colonizers. Because only 13 sites were sampled in 2004, additional testing is required to validate this classification scheme for lepidopteran communities in other tallgrass prairie systems.

larger local populations and may also generate a greater number of emigrants from neighboring patches (Gaston 1988, Brown 1995, Cowley et al. 2001). If passive sampling is, in fact, the dominant process contributing to species membership in newly restored prairies, the goal of restoring many populations of rare, prairieobligate species will be quite difficult to achieve because these species may only establish at a small subset of sites within the region regardless of restoration effort (e.g., see "late colonizers" in Table 5).

If moth community composition within restored habitats were solely a function of the most regionally abundant, generalized species colonizing patches earliest (followed over time by increasingly rare species), new restorations would be expected to strongly overlap in moth composition (i.e., possess low $\beta$-diversity) with

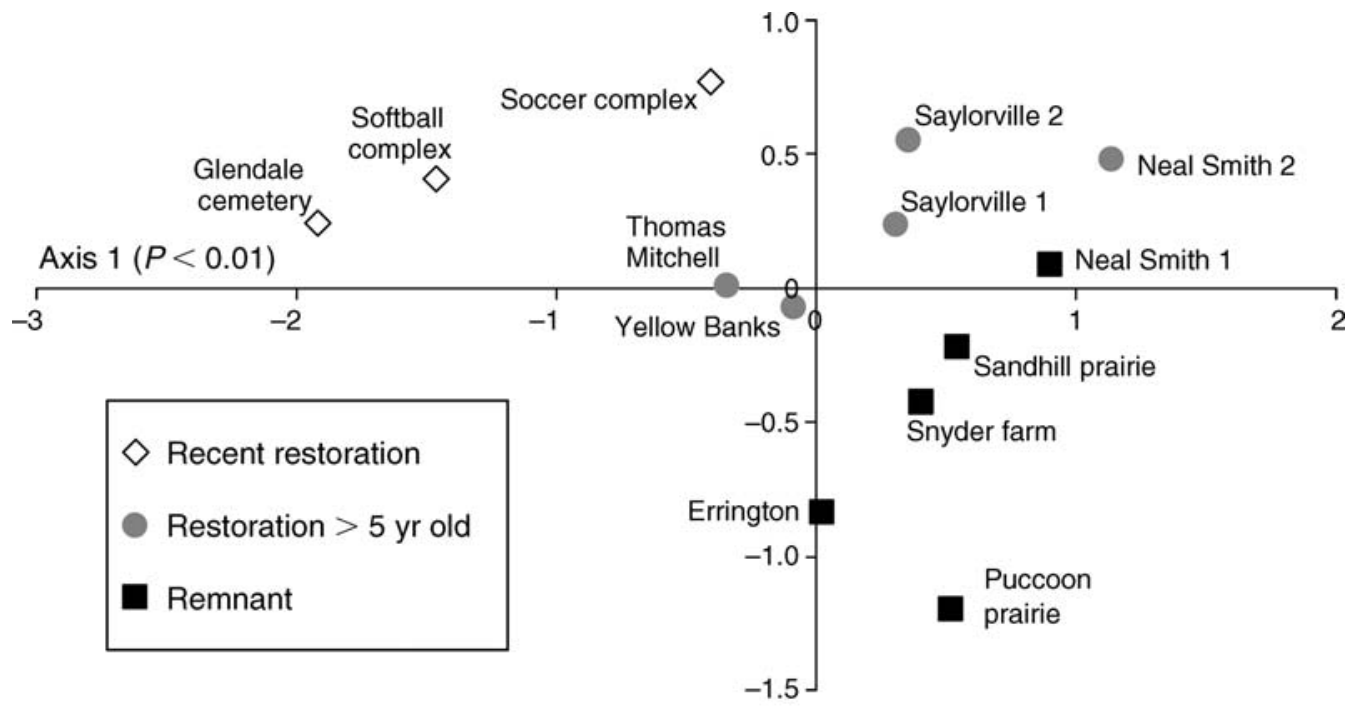

Axis $2(P<0.01)$

FIG. 2. Results of NMDS ordination for moth communities in 13 tallgrass prairie remnants and restorations (grouped into newly planted sites and older restorations). The $P$ values denoting the significance of each ordination axis were obtained from 1000 Monte Carlo randomizations of the data. Site names and descriptions appear in Table 1. 
only cosmopolitan species present (Holl 1996, Puyravaud et al. 2003, Summerville et al. 2005). As progressively rare species colonized a smaller fraction of sites, community composition of moths would be expected to diverge over time. Instead, we detected fairly large differences in moth community composition among the three newly planted sites, a result that may be attributable to the relatively forb-rich plantings attracting different suites of moths compared to a grass-dominated site (see Table 1). Furthermore, only one older prairie restoration (age $9 \mathrm{yr}$ ) appeared to be approaching the species composition present within native prairie remnants. Even when species richness of moths was similar in restorations and remnants, restored moth communities were much more dominated by grassand legume-feeding species (see also McIntyre and Thompson 2003). Holl (1996) noted a similar pattern for moth communities on reclaimed mine sites. Initially, the diversity of the plant species used to revegetate a site was correlated with significant variation in lepidopteran species composition among sites, but over time recolonization of sites slowed down or even halted completely, leaving old restorations $(>5 \mathrm{yr})$ relatively similar in composition. Rare or specialized species remained poorly represented in restored habitats up to 25 years following revegetation (see also Summerville et al. 2005).

We interpret the differences in moth communities among sites to indicate that recolonization of restored habitats must contain a substantial deterministic component that is related to differences in host plant preferences among species. In central Iowa, moth species with larvae known to feed on legumes were found at a much larger fraction of prairie sites than species known to feed on Asteraceae or other less speciose prairie forb families. This effect may be attributable to the fact that many legume-feeding moths are capable of utilizing Medicago sativa (alfalfa), Trifolium spp. (clovers), or Melilotus spp. (sweet clovers), which are commonly found in pastures and other disturbed habitats within the greater agricultural landscape (Robinson et al. 2002). A similar process may also contribute to the widespread occurrence of the graminoid-feeding Crambidae within newly restored systems; the surrounding landscape matrix may serve as a significant reservoir for species with such generalized diets (Krauss et al. 2003, Bergman et al. 2004). In this case, the floristic composition of the surrounding landscape may be as important to faunal recolonization as the diversity of the seed mix used to restore a prairie (Ouin et al. 2004, Waltz and Covington 2004). In contrast, many moth species known to feed on Asteraceae are only reported to feed on species within a particular genus (e.g., many Olethreutine moths described by Miller [1987]). Plant species in the genera Bidens, Silphium, Ratibida, Aster, and Helianthus tend to be infrequently encountered in the greater landscape and only achieve moderate to high cover values in restorations when forb : grass seed ratio used to revegetate a site is $\sim 1: 3$ (e.g., Neal Smith 2,
Table 1; see also Kindscher and Tieszen 1998). Seed mixes used to restore prairies, however, are not always so balanced (e.g., Table 1), and critiques of restored prairies often emphasize that prairie reconstructions lack floristic heterogeneity more commonly observed in prairie remnants (e.g., Rosburg 2001). Because we did not find a significant difference in species richness between prairie remnants and restorations, we suggest that prairie remnants contain higher levels of $\beta$-diversity compared to restorations that all tend to support a similar subset of grass- and legume-feeding moths.

One solution to the absence of certain moth feeding groups would be to increase forb diversity and cover within a site (Summerville 2004). If the landscape surrounding a restoration is incapable of supporting as many aster- or mint-feeding moth species, however, supplementing forb diversity within a site will not greatly accelerate the rate of species recolonization (Ouin et al. 2004). We suspect that this is one of the major reasons restored systems appear to reach a limit to species reaccumulation relative to remnant habitat. Managed landscapes are themselves a filter through which species from the regional pool must pass, and restorations in highly agricultural landscapes will likely regain only disturbance-tolerant lepidopterans (see also Holl 1996). Thus, our data also suggest that the most practicable method for restoring prairie lepidopteran communities will be to surround native remnants with planted prairie habitats. Because remnants appear to contain moth species that are unable to persist in the broader landscape mosaic of central Iowa, using restorations to buffer core prairie habitats should increase recolonization rates of newly planted patches. We also note that moth community composition exhibited some degree of spatial dependence; sites closer in space contained similar moth communities regardless of whether the sites were remnants or restorations (see also Luoto et al. 2001). This may be an encouraging result for a number of reasons. First, it suggests that the moth community within prairie remnants can favorably influence species composition in a restored site over time even if the two sites are not connected. Second, the potential for interactions between communities suggests that populations of prairie moths in restored habitats could "rescue" populations in remnant habitat following stochastic extinction (Cowley et al. 2001). Finally, spatial dependence suggests that by clustering restorations and isolated remnants, ecologists may be able to recreate functional metacommunity dynamics across spatial scales. The challenge here will be to shift restoration goals away from creating single sites that contain every desirable species in favor of restoring functional landscapes in which all species may be present but not found at every site.

\section{ACKNOWLEDGMENTS}

The project was supported by the National Research Initiative of the USDA Cooperative State Research, Education and Extension Service, grant number 2005-35101-15337 as well 
as from grants from the National Geographic Society, the National Aeronautic and Space Administration, the Iowa Science Foundation, and Drake University. N. Gilbertson, P. Drobney, L. Lown, S. Rolfes, J. McGovern, L. Elliot, J. Petersen, and D. Howell granted permission to us to sample moths from prairie restorations and remnants throughout central Iowa. M. Lewis contributed her assistance to the field sampling. R. Brown, R. Hodges, W. Miller, M. Sabourin, E. Metzler, and G. Balogh contributed their considerable expertise to identification of species outside our expertise. Finally, we thank T. Crist and three anonymous reviewers for comments and discussion that greatly improved this manuscript.

\section{Literature Cited}

Bergman, K.-O., J. Askling, O. Ekberg, H. Ignell, H. Wahlman, and P. M. Milberg. 2004. Landscape effects on butterfly assemblages in an agricultural region. Ecography 27:619-629.

Blackburn, T. M., and K. J. Gaston. 2003. Macroecology: concepts and consequences. Blackwell Science, Oxford, UK.

Brändle, M., S. Öhlschläger, and R. Brändle. 2002. Range sizes in butterflies: correlation across scales. Evolutionary Ecology Research 4:993-1004.

Brown, J. H. 1995. Macroecology. University of Chicago Press, Chicago, Illinois, USA.

Chao, A. 1987. Estimating the population size for capturerecapture data with unequal catchability. Biometrics 43:783791.

Chase, J. M. 2003. Community assembly: when should history matter? Oecologia 136:489-498.

Coleman, B. D., M. A. Mares, M. A. Willig, and Y.-H. Hsieh. 1983. Randomness, area, and species richness. Ecology 63: 1121-1133.

Cornell, H. V., and J. H. Lawton. 1992. Species interactions, local and regional processes, and limits to species richness of ecological communities: a theoretical prospective. Journal of Animal Ecology 61:1-12.

Cornell, H. V., and J. O. Washburn. 1979. Evolution of the richness-area correlation for cynipid gall wasps on oak trees: a comparison of two geographic areas. Evolution 33:257274.

Covell, C. V. 1983. Eastern moths. Houghton Mifflin Company, Boston, Massachusetts, USA.

Cowley, M. J. R., C. D. Thomas, D. B. Roy, R. J. Wilson, J. L. León-Cortés, D. Gutiérrez, C. R. Bulman, R. M. Quinn, D. Moss, and K. J. Gaston. 2001. Density-distribution relationships in British butterflies. I. The effect of mobility and spatial scale. Journal of Animal Ecology 70:410-426.

Dominick, R. B., et al. 1971-2005. The Moths of American north of Mexico. Fascicles 5.1-27.3. The Wedge Entomological Research Foundation, Washington, D.C., USA.

Forbes, W. M. T. 1923. Lepidoptera of New York and neighboring states. Part 1: primitive forms. Cornell University Agricultural Experiment Station, Ithaca, New York, USA.

Fukami, T. 2004. Community assembly along a species pool gradient: implications for multiple-scale patterns of species diversity. Population Ecology 46:137-147.

Garciá, D., and R. Zamora. 2003. Persistence, multiple demographic strategies, and conservation in long-lived Mediterranean plants. Journal of Vegetation Science 14: 921-927.

Gaston, K. J. 1988. Patterns in the local and regional dynamics of moth populations. Oikos 53:49-57.

Gaston, K. J., and D. Reavey. 1989. Patterns in the life histories and feeding strategies of British macrolepidoptera. Biological Journal of the Linnean Society 37:367-382.

Graham, M. H. 2003. Confronting multicollinearity in ecological multiple regression. Ecology 84:2809-2815.

Holl, K. 1996. The effect of coal surface mine reclamation on diurnal lepidopteran conservation. Journal of Applied Ecology 33:225-236.
Holt, R. D. 1993. Ecology at the mesoscale: the influence of regional processes on local communities. Pages 77-88 in R. E. Ricklefs and D. Schluter, editors. Species diversity in ecological communities. Chicago University Press, Chicago, Illinois, USA.

Jordan, W. R., M. E. Gilpin, and J. D. Aber. 1987. Restoration ecology: a synthetic approach to ecological research. Cambridge University Press, London, UK.

Kindscher, K., and L. L. Tieszan. 1998. Floristic and soil organic matter changes after 5 and 35 years of native tallgrass prairie restoration. Restoration Ecology 6:181-197.

Koh, L. P., N. S. Sodhi, and B. W. Brook. 2004. Ecological correlates of extinction proneness in tropical butterflies. Conservation Biology 18:1571-1578.

Krauss, J., I. Steffan-Dewenter, and T. Tscharntke. 2003. Local species immigration, extinction, and turnover of butterflies in relation to habitat area and habitat isolation. Oecologia 137: 591-603.

Lawton, J. H. 1990. Species richness and population dynamics of animal assemblages: patterns in body size, abundance, and space. Philosophical Transactions of the Royal Society London B 330:283-291.

Lewis, M. N., R. M. Steichen, and K. S. Summerville. In press. The diversity of moths in tallgrass prairies of Iowa: a preliminary assessment. Journal of the Iowa Academy of Science.

Liebold, M. A., M. Holyoak, N. Mouquet, P. Amarasekare, J. M. Chase, M. Hoopes, R. D. Holt, J. B. Shurin, R. Law, D. Tilman, M. Loreau, and A. Gonzalez. 2004. The metacommunity concept: a framework for multi-scale community ecology. Ecology Letters 7:601-613.

Lockwood, J. L., and S. L. Pimm. 1999. When does restoration succeed? Pages 363-392 in E. Weiher and P. Keddy, editors. Ecological assembly rules: perspectives, advances, retreats. Cambridge University Press, London, UK.

Longino, J. T., J. Coddington, and R. K. Colwell. 2002. Estimating species richness in three different ways. Ecology 83:689-703.

Luoto, M., M. Kuussaari, H. Rita, J. Salminen, and T. von Bonsdorff. 2001. Determinants of distribution and abundance in the clouded appolo butterfly: a landscape ecological approach. Ecography 24:601-618.

McCune, B., and J. B. Grace. 2002. Analysis of ecological communities. MjM Software Design, Gleneden Beach, California, USA.

McIntyre, N. E., and T. R. Thompson. 2003. A comparison of Conservation Reserve Program habitat plantings with respect to arthropod prey for grassland birds. American Midland Naturalist 150:291-302.

Metzler, E., J. A. Shuey, L. A. Berge, R. A. Henderson, and P. Z. Goldstein. 2005. Contributions to the understanding of tallgrass prairie-dependent butterflies and moths and their biogeography in the United States. Ohio Biological Survey, Columbus, Ohio, USA.

Miller, W. E. 1987. Guide to the Olethreutine moths of midland North America (Tortricidae). United State Department of Agriculture, Handbook 660, Washington, D.C., USA.

Nagelkerke, N. J. D. 1991. A note on the general definition of the coefficient of determination. Biometrika 78:691-692.

New, T. R. 1999. Limits to species focusing in insect conservation. Annals of the Entomological Society of America 92:853-860.

Novotny, V., S. E. Miller, L. Cizek, J. Leps, M. Janda, Y. Basset, G. D. Weiblen, and K. Darrow. 2003. Colonising aliens: caterpillars (Lepidoptera) feeding on Piper aduncum and $P$. umbellatum in rainforests of Papua New Guinea. Ecological Entomology 28:704-717.

Ouin, A., S. Aviron, J. Dover, and F. Burel. 2004. Complementation/supplementation of resources for butterflies in agricultural landscapes. Agriculture, Ecosystems, and Environment 103:473-480. 
Philippi, T. E. 1993. Multiple regression: herbivory. Pages $183-$ 210 in S. M. Scheiner and J. Gurevitch, editors. Design and analysis of ecological experiments. Chapman and Hall, New York, New York, USA.

Piegorsch, W. W., and A. J. Bailer. 1997. Statistics for environmental biology and toxicology. Chapman and Hall, London, UK.

Puyravaud, J.-P., C. Dufour, and A. Subramanian. 2003. Rainforest expansion mediated by successional processes in vegetation thickets in the Western Ghats of India. Journal of Biogeography 30:1067-1081.

Ricketts, T. H., E. Dinerstein, D. M. Olson, C. J. Loucks, W. M. Eichbaum, D. A. DellaSalla, K. C. Kavanagh, P. Hhedao, P. T. Hurley, K. M. Carney, R. A. Abell, and S. Walters. 1999. Terrestrial ecoregions of North America: a conservation assessment. Island Press, Covalo, California, USA.

Robinson, G. S., P. R. Ackery, I. J. Kitching, G. W. Beccaloni, and L. M. Hernández. 2002. Hostplants of moth and butterfly caterpillars North of Mexico. Memoirs of the American Entomological Institute 69:1-824.

Rosburg, T. R. 2001. Iowa's prairie heritage: from the past, through the present, and into the future. Pages 1-14 in N. P. Bernstein and L. J. Ostander, editors. Proceedings of the 17th annual North American Prairie Conference. North Iowa Area Community College, Mason City, Iowa, USA.

SAS Institute. 2000. SAS for Windows: release 6.12. SAS Institute, Cary, North Carolina, USA.

Shurin, J., and D. S. Srivastava. 2004. New perspectives on local and regional diversity: beyond saturation. Pages 271290 in M. Holyoak, M. Liebold, and R. Holt, editors. Metacommunity theory. University of Chicago Press, Chicago, Illinois, USA.

Spitzer, K., M. Rejmánek, and T. Soldán. 1984. The fecundity and long-term variability in abundance of noctuid moths (Lepidoptera: Noctuidae). Oecologia 62:91-93.

Stoner, K. J. L., and A. Joern. 2004. Landscape vs. local habitat scale influences to insect communities from tallgrass prairie remnants. Ecological Applications 14:1306-1320.

Summerville, K. S. 2004. Functional groups and species replacement: testing for the effects of habitat loss on moth communities. Journal of the Lepidopterists Society 58:129132.

Summerville, K. S., M. J. Boulware, J. A. Veech, and T. O. Crist. 2003. Spatial patterns of lepidopteran biodiversity in eastern deciduous forests and implications for conservation. Conservation Biology 17:1045-1057.

Summerville, K. S., and T. O. Crist. 2003. Determinants of lepidopteran species diversity and composition in eastern deciduous forests: roles of season, region, and patch size. Oikos 100:134-148.

Summerville, K. S., R. M. Steichen, and M. N. Lewis. 2005. Restoring lepidopteran communities to oak savannas: contrasting influences of habitat quantity and quality. Restoration Ecology 13:120-128.

Temperton, V. M., R. J. Hobbs, T. Nuttle, and S. Halle, editors. 2004. Assembly rules and restoration ecology. Island Press, Covelo, California, USA.

Townsend, C. R., S. Dolédec, and M. R. Scarsbrook. 1997. Species traits in relation to temporal and spatial heterogeneity in streams: a test of habitat template theory. Freshwater Biology 37:367-387.

Waltz, A. E. M., and W. W. Covington. 2004. Ecological restoration treatments increase butterfly richness and abundance: mechanisms of response. Restoration Ecology 12:8596.

Weiher, W., and P. Keddy. 1999. Ecological assembly rules: perspectives, advances, retreats. Cambridge University Press, London, UK.

Winter, W. D., Jr. 2000. Basic techniques for observing and studying moths and butterflies. Memoirs of the Lepidopterists Society Number 5. Lepidopterists Society, Clinton, New York, USA.

Yela, J. L., and M. Holyoak. 1997. Effects of moonlight and meteorological factors on light and bait trap catches of noctuid moths. Environmental Entomology 2:1283-1290.

Zobel, M. 1997. The relative role of species pool in determining plant species richness: an alternative explanation of species coexistence? Trends in Ecology and Evolution 12:266-269.

Zobel, M., M. Otsus, J. Liira, M. Moora, and T. Möls. 2000. Is small-scale species richness limited by seed availability or microsite availability? Ecology 81:3274-3282. 